\title{
Appreciating the Experiences and Expertise of Adult Students
}

\author{
Jeremy Bohonos
}

A student in her mid-50s recently told me that when she asked for guidance from a university staff member that the individual informed her that "she was in college now and needed to start acting like an adult." For a mother of three and expectant grandmother, this was shocking, especially coming from someone who was about 15 years her junior. The story also stunned me and helped me to see the importance of appreciative approaches when working with adult students. We, as professionals, need to honor and respect the experiences and achievements of these individuals.

Given the brevity of many student interactions, I understand that staff members may not often get a chance to understand their students' specific personal and professional accomplishments, but when working with adult learners, we must start with the assumption that they have them. I am fortunate that I split my time between outreach and career advising. As a Career Advisor, I get to see the resumes of my adult students and speak in more detail about their many achievements. Often times, after spending just a few moments learning about my students, I feel humbled that they are seeking my input on course selection and other academic issues. In any other context, upper level executives, grandparents, community and civic leaders, as well as policemen or military personal would be seen as my social superiors. In the realm of academia, however, I am the expert that these same people need to come to for help navigating the university. It is an honor and a privilege to meet them and do my best to facilitate their academic success.

Adult students are usually deeply knowledgeable people with incredible life experience as well as expertise in their career fields. This knowledge, however, may not translate into specific understandings of academic jargon and protocol. People who have been out of school a long time might need some special assistance getting acculturated to a university. As professionals in higher education, we need to understand that this specific lack of knowledge is not indicative of a lack of commitment or ability.

The professional knowledge level of my students is astounding. I could not hope for a better collection of experts to walk through my door than the adult students whom I serve. I also could not hope to give advice in a more supportive and informative way than I have received it from my students. As a General Studies Career Advisor, I have to know enough about any number of career fields to give

Jeremy Bohonos (Jbohonos@iupui.edu) is a Career Advisor for the Center for Adult and Lifelong Learning \& Divisions of Continuing Studies at Indiana University Purdue University Indianapolis. 
useful feedback to students who are looking to make career moves. When I first took the position, I was overwhelmed when I started to realize how much I needed to learn about the myriad of jobs open to General Studies graduates. I started to breathe easy when I realized that, for every student I have that wants to break into a certain industry or occupational area, I have another already in a similar role. I benefit daily from students who explain the ins and outs of dental assisting, working as a paralegal, horticultural research, web development, directing notfor-profit organizations, underwater welding, computer programming, technical writing, or running industrial contracting companies.

The next time you find yourself needing to put in a little extra time with an adult student, I challenge you to ask yourself how much extra help you would need if you found yourself in the world of risk management or tax accounting. This is not an empty challenge. My students often offer their expertise regarding these fields and others. When they share their knowledge and expertise, they do so with a degree of detail and concern that could be very instructive to any student service professional. They take the time to explain complex definitions and procedures, provide me with referrals to people active in the field, and invite me to follow up with them if I need assistance in the future. My students are the perfect advisors, and I try to follow the models that they exemplify.

When we talk about theoretical models for working with students, we can consider a variety of approaches. I believe, however, that if we made the time to hear their stories and understand the expertise of all our adult learners, we would agree that we must look first to appreciative approaches that validate experience from outside of higher education when working with adults.

\section{References}

Dewey, J. (1938). Experience and education. New York: Simon \& Schuster Bloom, J. and Martin, N.A. (2002). Incorporating appreciative inquiry into academic advising. The Mentor: An Academic Advising Journal, 4(3). http://dus.psu.edu/mentor/old/articles/020829jb.htm

Bloom, J. L., Hutson, B. L., \& He, Y. (2008). The appreciative advising revolution. Champaign, IL: Stipes Publishing.

Truschel, J. (2008). Does the use of appreciate advising work? The Learning Assistance Review, 13(2), 7-16. 